\title{
A modernidade
}

\section{e as razōes do Manifesto}

MARCO AURÉLIO NOGUEIRA

\begin{abstract}
A o lONGo do ÚlTIMO SÉCUlo e meio o Manifesto do Partido Comunista redigido entre janeiro e fevereiro de 1848 por Marx e Engels e publicado em Londres logo depois como parte da estratégia de divulgaçáo do entáo nascente movimento dos trabalhadores - tornou-se o texto político mais lido e difundido da história contemporânea. Foi consumido voraz e apaixonadamente tanto pelos que viram nele a ante-sala de uma nova era para a humanidade quanto por seus inúmeros adversários. Tornou-se objeto de dedicada, exaustiva e meticulosa pesquisa por parte de seus admiradores, muitos dos quais convencidos de que ali estaria a chave para a explicação dos mistérios e sutilezas da história humana. Houve também os que preferiram atribuir ao texto o status de guia autorizado para a ação, enquanto outros entregaram-se à tarefa de submetê-lo a verdadeiros ritos de culto e adoração, cercados de uma liturgia que seguramente horrorizaria seus autores. Recebeu tratamento menos empenhado e regra geral acrítico da parte de seus contestadores, muitos dos quais o repeliram com veemência injustificável, incapazes de encontrar no texto algo mais do que as raízes do totalitarismo moderno, da estatização e do b́dio de classe.
\end{abstract}

O Manifesto sobreviveu a tudo isso. Quando hoje, em muitas partes do mundo, sucedem-se manifestaçōes e eventos destinados a registrar seu sesquicentenário e, ao mesmo tempo, diversas vozes se alçam para decretar a morte do socialismo e a vitória definitiva do capitalismo, o texto ainda consegue reluzir, impondo-se com vigor exuberante e excepcional poder de fascinação. Não há quem permaneça indiferente ao se pôr em contato com ele. Quem não se inquiete com o cenário por ele descrito com tanta objetividade e paixão. Quem náo se pergunte se, no fundo, náo estaria ali, naquelas poucas e contundentes páginas, uma saída para os impasses que insistem em atormentar homens e mulheres de todas as épocas. Impasses que se repóem a cada dia sob formas novas, mais perversas e sutis, como que a simbolizar a grandeza e a dureza da vida, as promessas e os obstáculos do progresso técnico, da produtividade, do engenho humano e da expansáo do intercâmbio entre os povos. Marx e Engels cantaram em prosa, sintetizando-a, toda a série de grandes utopias típica da história do pensamento político. Puseram em outro patamar a aposta racionalista, 
iluminista e humanista no homem como ser eminentemente vocacionado para o progresso, para a história, para a convivência dignificante na pólis. Realizaram-se desse modo como clássicos no melhor sentido da palavra: "intérpretes de seu próprio tempo que permanecem atuais em todos os tempos", como afirmou certa vez o filósofo italiano Valentino Gerratana.

Essa talvez seja a primeira razáo da capacidade que teve o Manifesto de resistir ao tempo. Mas o texto também seduz porque procura, inspirado numa ousada proposta filosófica e empenhado num deliberado esforço teórico para dessacralizar o mundo dos homens, afirmar uma identidade. Identidade, como se sabe, de uma parte da sociedade - de um partido enquanto idéia e programa, não tanto enquanto forma organizacional. Mas uma parte vocacionada para se fazer todo, expressar a unificação do gênero humano e a superação das diversas diferenciaçóes sócio-econômicas que opunham os homens uns aos outros. Põe-se como arauto do protagonismo de um novo sujeito, enraizado no mundo do trabalho industrial e despojado de toda propriedade e de toda a possibilidade de se emancipar, diretamente interessado, por isso mesmo, no estabelecimento das bases de uma nova convivência, quer dizer, disposto a lutar por uma revoluçáo social profunda, que viabilizasse a constituição de uma sociedade democrática, igualitária, justa. Um sujeito, em suma, que não tendo "nada a perder a não ser suas cadeias", tinha "um mundo a ganhar".

A identidade de que falavam Marx e Engels nascia de um impetuoso movimento de mudança: a revoluçáo capitalista, liderada pela burguesia européia e destinada a espalhar seus frutos pelo mundo. A descriçáo da natureza dessa revoluçáa, de seus efeitos sobre a vida dos homens e de suas contradiçóes, talvez seja imbatível em poder de convencimento. Nunca como naquelas páginas o capitalismo foi apresentado com cores tão fortes. Nunca o socialismo foi mostrado como algo tão viável: afinal, do ventre da revoluçáo burguesa parecia saltar o destino inovador da humanidade, uma transformaçáo de qualidade absolutamente nova, que tendia a comprometer os homens para sempre, a inseri-los na trilha do progresso, do bem-estar, da solidariedade, da cosmopolitização, a arrancá-los do "idiotismo da vida rural". O discurso não pecaria por falta de estilo: "O contínuo revolucionamento da produçáo, o abalo constante de todas as condiçóes sociais, a incerteza e a agitação eternas distinguem a época burguesa de todas as precedentes. Todas as relaçóes fixas e cristalizadas, com seu séquito de crenças e opinióes tornadas veneráveis pelo tempo, são dissolvidas e as novas envelhecem antes mesmo de se consolidarem. Tudo o que é sólido e estável se volatiliza, tudo o que é sagrado é profanado, e os homens sáo finalmente obrigados a encarar com sobriedade e sem ilusóes sua posição na vida, suas relaçōes recíprocas". $O$ que libertava trazia consigo o seu oposto: o sólido, o que era sagrado, conhecido 
e valorizado como referência para a vida - relaçôes familiares, crenças, afetos, sensaçóes, coisas que garantiam alguma inteireza ao indivíduo - convertia-se em mercadoria. Tudo tenderia, assim, a se fragmentar e a se transformar em objeto de cálculos frios, embalados pela progressão de uma racionalidade de novo tipo, eminentemente instrumental. Esvaziavam-se, desse modo, os tradicionais recursos de que dispunham os indivíduos para imprimir um sentido ao mundo: libertavamse, mas também perdiam boa parte da magia que dava graça à vida. Mais tarde, Weber falaria em "desencantamento do mundo" (1).

Com base nessa dinâmica frenética e (auto)subversiva - nesse modo de vida que não pode existir sem "revolucionar continuamente todo o conjunto das relaçōes sociais", sem atirar os homens na "incerteza e na agitação eternas" -, o socialismo tornava-se um programa factível. Saía-se do sonho para a realidade. Tudo estaria, a partir de entáo, em condiçóes de ser realizado por quem se mostrasse disposto a construir organizaçôes, a mobilizar consciências, a repor e estabelecer vínculos sociais, a acenar com novos projetos de vida, a mergulhar em árduos e prolongados embates políticos. Afinal, a burguesia não se cansava de "produzir seus próprios coveiros", de fornecer incessantes "elementos de educaçáo, isto é, armas contra si mesma" aos proletários, dando a eles condiçóes de se realizar como "classe que traz o futuro nas mãos". Com isso, o socialismo podia ser concebido como algo mais do que uma mera "socialização da miséria", ou seja, como um efetivo passo adiante: superar o capitalismo, apoiando-se precisamente nas "poderosas e colossais" forças produtivas que a burguesia havia despertado no seio do trabalho social, mais imponentes do que as forças criadas por "todas as geraçôes passadas em conjunto".

O Manifesto tinha seus limites, é evidente. Era prisioneiro da mesma juventude do movimento de que cantava as possibilidades futuras. Não concebia o processo político por uma via que não fosse a da "guerra civil", a da luta violenta entre a classe que enriquecia sempre mais e a classe que empobrecia sem cessar. Passou batido pelo problema de saber como poderiam os proletários, reduzidos à pauperizaçáo absoluta, protagonizar uma revoluçáo. Muitas de suas propostas soam hoje como ingênuas ou anacrônicas, como já haviam antevisto seus próprios autores em 1872, quando sugeriram que não se atribuísse "nenhuma importância particular às medidas revolucionárias" estabelecidas no texto. $O$ Manifesto não conseguia visualizar os efeitos da integração dos trabalhadores, extrair os desdobramentos práticos da monumental "socialização política" que se seguiria ao avanço da industrializaçáo e da urbanizaçáo e que, no século XX, levaria os países ocidentais à experiência do Welfare State, do sufrágio universal, das reformas sociais, dos ganhos educacionais e científicos, do crescimento cultural das grandes massas, em suma, da democratização. Não fazia isso, dentre outras coisas, porque 
seus autores ainda engatinhavam em termos teóricos e apostavam que a revoluçăo socialista era iminente, imposta que estava pelos próprios problemas de realização do capitalismo.

Além do mais, como evitar tais limites 150 anos atrás? $O$ Manifesto era filho do tempo. E o tempo não podia deixar de impor, às emergentes massas de trabalhadores, uma perspectiva revolucionária, de confronto, de combate. A democracia não era uma realidade já evidenciada, nem se encontrava funcionando na grande maioria dos países do mundo. A "socialização da política" seria um fenômeno posterior a 1848 , derivado em boa medida das próprias lutas do movimento operário, ao menos em parte referenciado pelas idéias de Marx e do Manifesto (que ganhariam expressão progressivamente, ao ponto de jogar um papel de peso na Associaçáo Internacional dos Trabalhadores, nos anos 60, e no processo de constituiçáo de numerosos partidos social-democratas a partir de então). Décadas depois, Marx e Engels iriam recompor os termos de seu programa de ação: sem abrir máo das conviç̧ôes revolucionárias e do entendimento de que o capitalismo estava fadado a funcionar sempre na crise (mas não necessariamente a desaparecer pelo mero jogo de suas contradiçóes econômicas) - tal como o feiticeiro "que já não pode controlar as potências infernais por ele postas em movimento" -, veriam com outros olhos as possibilidades de uma transiçâo de longo prazo, mais processual que diruptiva.

Se devidamente contextualizado e posto em sintonia com a história real em que nasceu e com a qual dialogou, o texto de 1848 compensa folgadamente suas fraquezas. Até mesmo por isso, tornou-se muito mais do que o manifesto de um programa político, convertendo-se num libelo emancipador de largo fôlego, capaz de emocionar por seu estilo pungente e indignado. Balizando a reflexão da esquerda nos mais diversos países, acabaria colado ao imaginário mesmo do mundo contemporâneo.

Hoje, quando se comemoram os 150 anos do Manifesto, não cansamos de nos surpreender com a complexidade e os desafios da época. Talvez se possa dizer que estamos imersos em uma fase mais avançada do mesmo processo de mudanças radicais que em 1848 mobilizou a energia política e intelectual de dois jovens comunistas alemães. São reais e gigantescos os problemas com que nos defrontamos, mas são igualmente reais e gigantescas as possibilidades de que se coloque em curso uma etapa histórica efetivamente nova para a humanidade. Hoje, como ontem, continuam vivas (mesmo que sedadas ou adormecidas) as expectativas e a disposição de engajamento de homens e mulheres no mundo todo. Crise e mudança acelerada: esse o binômio com que temos de nos haver nessa transição verdadeiramente epocal que coincide com a chegada do século XXI. 


\section{A difícil arte de mudar}

Precisamente por alterar o sentido do tempo e mexer tanto com os fundamentos, as estruturas $e$ as representaçōes da ordem vigente, o binômio crise/mudança acelerada traz consigo duas grandes tentaçóes: a da resistência em nome de velhas postulaçóes e a da apologia dos novos dados da vida.

Não são reações que se excluam. Buscar apoio no passado - nas antigas verdades, nos conceitos comidos pelo tempo, nos sujeitos em extinçáo, nas frases surrupiadas de textos consagrados - tem muitos pontos de contato com o discurso dedicado a amplificar as novidades do presente. Ambos são comportamentos ingênuos, independentemente da virulência verbal com que possam apresentar seus argumentos e da maior ou menor sofisticação técnica de que os revestem. São igualmente impostos pela realidade, funcionando como atitudes típicas, das quais não conseguimos nos livrar e que em boa medida estáo entranhadas na natureza mesma do homem.

Voltar-se para o passado é um dos mais conhecidos comportamentos humanos. Trata-se de algo lógico em quem tem e faz história. No passado estão as verdades aprendidas, as certezas conquistadas, os fatores que nos dão segurança e identidade. Com o passado, conseguimos compensar as agruras do presente e as dúvidas com relação ao futuro. Quanto mais, aliás, uma época (uma comunidade, uma pessoa) vê cobrir-se de névoa sua visão do futuro, mais ela tende a buscar proteção no passado. Sobretudo os poetas sabem disso: "quando o futuro é incerto, o coração volta ao passado" (Gabriel Garcia Marquez). Mas não há quem não tenha experimentado na pele o problema, quem não tenha sido por ele desafiado, quem não tenha a ele dado alguma atenção. Agarrar-se ao passado é uma reação comuníssima, que desrespeita todos os credos e todas as disposiçóes subjetivas, aí incluídas as mais resolutamente revolucionárias, como costuma dizer o filósofo Leandro Konder. Trata-se de algo que sustenta o conservadorismo e o medo de mudar táo visceralmente inerentes ao mundo dos homens.

O que não significa que a desvalorização do passado, se chegar a ser possível e não for mero truque ideológico, traga em si alguma virtude. Ela, em boa medida, representa tão-somente a confissão de que o presente não vale muita coisa, não tem muito sentido nem pode ser visto como plataforma para a construçáo do futuro. A depreciação do passado - sua rejeição em bloco - só consegue mesmo impulsionar a adesão abstrata ao novo, ou seja, forçar o abandono de qualquer tentativa de pensar criticamente o que está nascendo, se constituindo ou se redefinindo. Entende-se assim a racionalidade dos que vêm o presente sem crise ou contradiçóes, como a negação absoluta do passado, como um tempo integrado 
apenas por coisas boas e positivas, realização plena de uma nova era. Trata-se de uma racionalidade fria e cega, incapaz de compreender que o presente "nada mais é do que a metade do espólio de um passado que se obstina em sobreviver" e o passado, "por suas regras, diferenças e semelhanças, nada mais do que a chave indispensável de todo e qualquer conhecimento do presente", como afirmou certa vez Fernand Braudel.

Sem a compreensão do passado, sem uma explicação crítica do presente e sem um projeto de futuro, é impossível dirigir a mudança. Não basta a mera repulsa ao presente: sua rejeição em nome de épocas pretéritas melhores, de convicçóes doutrinárias cristalizadas, de compromissos anteriormente assumidos, de interesses prejudicados, de perspectivas políticas vazias de materialidade social. É preciso adicionar à crítica do presente uma proposta de futuro, entender em que medida e por que motivos o hoje prepara o amanhã, delinear quais futuros possíveis temos diante de nós e quais os caminhos que se nos oferecem para que os alcancemos.

Hoje, quando o mundo se dobra à grave ausência de perspectivas e à aguda crise de referências, devemos nos empenhar sinceramente para olhar além. Não é aceitável que nos entreguemos ao diagnóstico de uma "crise que piora sempre mais", que é mortífera em sua magnitude e abrangência, que nos sufoca e impede o vislumbre de qualquer saída. Não basta denunciar os culpados pelas mazelas do presente, sejam eles governantes, classes, interesses ou megatendências. Não basta acumular dados que comprovem que hoje estamos piores do que ontem, que denunciem retrocessos e vitimizaçóes amorais ou que relativizem a euforia dos adoradores de tudo o que é novo. É preciso ir além. É preciso descobrir no presente os elementos que anunciam o futuro, que condensam o que de melhor fizemos e que por isso mesmo podem alicerçar um projeto razoável de mundo. Apesar de tudo e em meio a terríveis conflitos e contradiçôes, a humanidade continua viva, conquistando novas possibilidades a todo momento, rompendo limites históricos que até então bloqueavam a autodeterminação, a liberdade, a inteligência, a criatividade, o diálogo de todos com todos. Não será esse um bom ponto de apoio para se ver além?

Nunca como hoje reuniram-se tantas condiçōes para uma construção inteligente do futuro. Esse é o grande produto da fase de radical mundialização do mundo em que nos encontramos: da desterritorialização, do avanço tecnológico e científico, das possibilidades de produção material, do salto gigantesco em termos de comunicação e acesso a informaçōes, do surgimento de novos espaços de troca e convivência, do aumento das chances de fundação de uma democracia de novo tipo. $\mathrm{O}$ mundo se desprovincianiza a olhos vistos, perde os vínculos 
estreitos com o território, vê abrirem-se verdadeiras fendas nas velhas soberanias, nas velhas estruturas, nas velhas instituiçōes, ou seja, em tudo aquilo com o que se construiu o progresso passado (mas com o que também se viabilizaram tantos horrores). Fiel à sua natureza, o capital continua a subverter incessantemente todas as bases produtivas, sócio-culturais e políticas da vida humana, a conduzir as sociedades a repentinos "estados de barbárie momentânea", a revolucionar constantemente todas as ordens, inclusive a sua própria, empurrando-nos todos para a "incerteza e a agitação eternas".

Subversão da ordem, que hoje concretamente produz um comportamento defensivo da esquerda (muitas vezes para preservar certos direitos e espaços conquistados no interior da própria ordem burguesa) e exige, ao mesmo tempo, empenho redobrado para que se restabeleçam as bases e a alma de uma subversão de outra qualidade, direcionada para a recomposição da unidade do gênero humano: uma nova unificação do homem no mundo, assentada na reciprocidade, no reconbecimento do outro, no revigoramento da comunidade, na democracia e na justiça social.

\section{A força do Manifesto}

No campo específico da esquerda, porém, há muito mais dúvidas que certezas, muito mais confusáo e falta de transparência do que identidades e propósitos claramente demarcados. Sequer se consegue deslindar, hoje, a presença dos comunistas. As indagaçóes se acumulam, sem trazer consigo uma correspondente profusáo de respostas. A perspectiva da luta de classes como motor da história e, também, na sua forma-limite, como porta de entrada do socialismo, deve ser mantida hoje, quando uma classe inteiramente estranha - a classe dos excluídos e dos sem-emprego - parece crescer e se multiplicar sem cessar, cortando as possibilidades de que se materialize a tendência percebida no Manifesto de um choque cada vez mais agudo entre burgueses e proletários? Seriam os excluídos os proletários do século que se aproxima? Quem é hoje o sujeito da revolução? Ainda faz sentido imaginar o comunismo como etapa mais avançada de socialismo, como organização inteiramente afastada da dinâmica mercantil e da propriedade privada, numa fase da história tomada pelo ideal consumista, pela apropriação individual, pela cultura da privacy? Seria a social-democracia - não enquanto rótulo de partidos políticos hoje existentes, mas como programa - a nomenclatura realista da grande utopia de Marx e Engels, proposição mais factível com as imposições de uma época firmemente assentada na mercantilização, no intercâmbio ampliado e, ao mesmo tempo, na convivência de diferentes formas de regulação (pelo mercado, pelo Estado, pela comunidade)? Podemos continuar alimentando a aposta no desaparecimento do Estado, na sua redução a mera 
administração das coisas", nesse mundo que exige sempre mais instâncias superiores de totalizaçáa, articulaçáo e equalização? $O$ que fazer com a questão democrática e com o seu lugar na transiçáo para uma sociedade socialista numa época em que náo se consegue sequer viabilizar a forma representativa da democracia e que talvez esteja a exigir, da esquerda, mais do que nunca, um esforço concentrado para salvar, renovar e reinventar a democracia em si mesma, sem adjetivos ou qualificaçóes?

O Manifesto não responde a qualquer dessas questóes. Seria absurdo exigir que o fizesse. Mas há nele um incontestável estímulo para que continuemos com os olhos pregados na realidade viva das coisas, nas possibilidades efetivas de uma transformação em sentido progressista, isto é, destinada a estabelecer as bases de uma nova convivência entre homens e mulheres, de uma unificação categoricamente superior do gênero humano. Afinal, a força desse texto vigoroso não está na apresentação de um programa pronto e acabado, fundado num conjunto de "princípios inventados por esse ou aquele reformador do mundo". Sua força repousa, ao contrário, no empenho de ser a "expressão geral de um movimento histórico que se desenrola sob nossos olhos". O próprio Marx náo se cansou de repetir que, para ele, comunismo era essencialmente "o movimento real que abole o estado de coisas existente". De resto, o que esperar de um texto que se mostra legivel 150 anos depois de escrito senão uma perspectiva de análise, se se preferir um método?

A grande sugestão a se extrair do Manifesto é a de que as armas da crítica náo podem ser entregues jamais. Até mesmo porque ainda vivemos no mundo do capital - com toda a sua desumanidade visceral, com todo o embrutecimento subjetivo por ele alimentado, com todas as suas desigualdades e injustiças, mas também com toda a sua capacidade de impulsionar a produçăo, universalizar o intercâmbio, ativar gigantescas forças sociais, mostrar "o que pode realizar a atividade humana" -, a crítica radical, a crítica que vai à raiz das coisas para revelá-las em sua inteireza e superá-las, continua na ordem-do-dia. Não há como imaginar uma situaçáo na qual "o livre desenvolvimento de cada um seja a condiçáo do livre desenvolvimento de todos" sem o aprofundamento da crítica ao império da economia (do mercado e da moeda) e do Estado (da força e da potência) sobre a sociedade e sobre o indivíduo. Não há como caminhar nessa direçáo sem uma reflexáo rigorosa sobre as possibilidades e a natureza do socialismo - uma reflexáo que seja simultaneamente despojada de preconceitos e dogmas principistas, aberta para uma visáo renovada da liberdade, do indivíduo e da democracia, inconformista, insatisfeita consigo mesma e, por isso, determinada a se reinventar a todo momento. 
Seriam necessárias outras razóes para que continuássemos a ler o Manifesto?

Nota

1 A respeito desses aspectos dilemáticos da modernidade, a partir dos quais tende a se generalizar a sensação de um típico mal-estar, indício de que os homens passam a traduzir certos traços da época como perda ou declínio, remeto ao belo e instigante ensaio de Charles Taylor, The malaise of modernity, de 1991 (edição italiana: Il disagio della modernità. Roma-Baris, Laterza, 1994).

Marco Aurélio Nogueira é professor do Departamento de Política da Faculdade de Ciências e Letras da Universidade Estadual Paulista (Unesp), campus de Araraquara, e pesquisador da Fundação do Desenvolvimento Administrativo (Fundap). Tradutor, dentre outros, do Manifesto Comunista (Editora Vozes, 1988) e autor de As possibilidades da política: idéias para a reforma democrática do Estado (Paz e Terra, 1998). 